\title{
Formation of Chromate Conversion Coatings on Al-Cu-Mg Intermetallic Compounds and Alloys
}

\author{
W. R. McGovern, ${ }^{a}, *$ P. Schmutz, ${ }^{b}, * *$ R. G. Buchheit, ${ }^{b, * *}$ and R. L. McCreery ${ }^{a, * *}$ \\ ${ }^{a}$ Department of Chemistry and ${ }^{b}$ Department of Materials Science and Engineering, The Ohio State University, Columbus, \\ Ohio 43210, USA
}

Chromium conversion coating (CCC) formation was monitored on copper-containing aluminum alloys AA2024-T3 and a specially cast $\mathrm{Al}_{x} \mathrm{Cu}_{y} \mathrm{Mg}_{z}$ ingot using Raman spectroscopy of the $860 \mathrm{~cm}^{-1}$ band. The $\mathrm{Al}_{x} \mathrm{Cu}_{y} \mathrm{Mg}_{z}$ ingot's different phases were compositionally analyzed with energy-dispersive spectroscopy (EDS) and Auger electron spectroscopy (AES) before and after treatments using commercial Alodine ${ }^{\mathrm{TM}} 1200 \mathrm{~S}$ chromium solution. Profilometry and Raman intensity of the $860 \mathrm{~cm}^{-1}$ band were used to gauge CCC film thickness on AA-2024-T3 alloy. A linear relationship between CCC thickness and the integrated $860 \mathrm{~cm}^{-1}$ band was shown to exist on AA-2024 alloy. Raman intensity of the $860 \mathrm{~cm}^{-1}$ band was also integrated and spatially mapped using commercially available software. These results were verified with AES depth profiling using an $\mathrm{Ar}^{+}$ion sputter. CCC formation was found to be slower on the $\mathrm{Al}_{x} \mathrm{Cu}_{y} \mathrm{Mg}_{z}$ phases with higher copper content. Similarly, in 2024-T3, CCC formation was suppressed on S-phase $\mathrm{Al}_{2} \mathrm{CuMg}$ and "depressed" $\mathrm{Al}_{20} \mathrm{Cu}_{2} \mathrm{FeMn}$ intermetallics of 2024 aluminum alloy. $\mathrm{Fe}(\mathrm{CN})_{6}^{3-/ 4-}$ adsorption on the $\mathrm{Al}_{x-}$ $\mathrm{Cu}_{y} \mathrm{Mg}_{z}$ ingot phases, $\mathrm{Cu}, \mathrm{Al}, \mathrm{Mg}$, and AA2024-T3 were characterized by Raman in the $2100 \mathrm{~cm}^{-1}$ range.

(c) 2000 The Electrochemical Society. S0013-4651(00)04-023-4. All rights reserved.

Manuscript submitted April 6, 2000; revised manuscript received August 17, 2000.

"Accelerated" chromate conversion coating (CCC) formulations are distinguished among all CCC types by the fact that they utilize a special chemical additive to increase coating weight, ${ }^{1}$ or increase the rate of the film forming $\mathrm{Cr}^{\mathrm{VI}}$ to $\mathrm{Cr}^{\mathrm{III}}$ reduction reaction. ${ }^{2}$ Ostensibly, accelerated CCCs are used on corrosion-prone $\mathrm{Al}-\mathrm{Cu}-\mathrm{Mg}$ and $\mathrm{Al}-$ $\mathrm{Zn}-\mathrm{Mg}-\mathrm{Cu}$ alloys to ensure maximum protection. ${ }^{3}$

Ferricyanide $\left[\mathrm{Fe}(\mathrm{CN})_{6}^{3-}\right]$ has been used as an accelerant in commercial CCC formulations since the 1960 s. ${ }^{1}$ Despite the long history, its role in coating formation has not been precisely established. Both $\mathrm{Fe}(\mathrm{CN})_{6}^{3-}$ and $\mathrm{Fe}(\mathrm{CN})_{6}^{4-}$ are readily detected in $\mathrm{CCCs}$ by various surface-sensitive techniques, supporting the notion that it contributes to coating weight by becoming part of the CCC film. ${ }^{1}$ For example, Treverton and Davies used X-ray photoelectron spectroscopy (XPS) and ion-beam etching to study accelerated CCCs formed on $99.8 \%$ pure $\mathrm{Al}$ substrates. ${ }^{4}$ Results indicated the presence of $\mathrm{Fe}(\mathrm{CN})_{6}^{4-13-}$ concentrated in the near-surface regions. It was suggested that the compound was probably present as a $\mathrm{CrFe}(\mathrm{CN})_{6}$ salt. However, the findings were insufficient to establish a clear role for $\mathrm{Fe}(\mathrm{CN})_{6}^{3-}$ in coating formation.

In subsequent studies aimed at clarifying their earlier work, these workers prepared accelerated CCCs on $99.8 \% \mathrm{Al}$ from a bath formulation based on commercial chemistries. ${ }^{5}$ XPS results indicated that $\mathrm{Fe}(\mathrm{CN})_{6}^{3-/ 4-}$ was present throughout the coating but was concentrated in the near-surface region. Mixed metal cyanides identified in the earlier study were now not present. Additionally, evidence of ferrocyanide $\left[\mathrm{Fe}(\mathrm{CN})_{6}^{4-}\right]$ was found. The authors equivocated on the significance of ferrocyanide determination since ferri- to ferrocyanide reduction in X-ray beams was known to occur. Despite these complications, it was proposed that the primary film growth reaction, chromate reduction, was stifled by adsorption of ferricyanide on the nascent CCC, thereby increasing the availability of free chromate for reaction with uncoated metal.

Hagans and Haas specifically considered film formation on $\mathrm{Cu}$ and Fe intermetallic compounds (IMCs) in studies of accelerated CCC formation on 2024-T3. ${ }^{6}$ Auger electron spectroscopy (AES), XPS, and ion-beam depth profiling were used to show that for coating formation times up to $3 \mathrm{~min}$, the film formation rate on various phases in 2024-T3 decreased in the order: matrix phase > $\mathrm{Cu}$ IMC > Fe IMC. After 5 min of immersion time, coating thickness appeared to be similar on the different phases. These workers proposed that ferrocyanide interacted with $\mathrm{Cu}$-rich IMCs to form $\mathrm{Cu}_{4} \mathrm{Fe}(\mathrm{CN})_{6}$ or

\footnotetext{
* Electrochemical Society Student Member.
}

** Electrochemical Society Active Member.
$\mathrm{Cu}_{2} \mathrm{Fe}(\mathrm{CN})_{6}$ and that these compounds promoted corrosion resistance by eliminating the galvanic couples that would otherwise form between the noble particles and the matrix phase.

Lytle et al. used a variety of surface analytical techniques, including X-ray absorption spectroscopy (XAS), X-ray absorption near edge spectroscopy (XANES), extended X-ray absorption fine structure (EXAFS), and Fourier transform infrared spectroscopy (FTIR) to study the chemistry of accelerated CCCs on 2024-T3 and 7075T6. ${ }^{7}$ Their results, made with low spatial resolution probes, showed $\mathrm{Fe}(\mathrm{CN})_{6}^{3-}$ present in the outermost $20 \AA$ of the CCC. Results appeared to show that $\mathrm{Fe}(\mathrm{CN})_{6}^{3-}$ was still present after salt-spray testing. Recently, Hughes et al. used XPS to study accelerated CCCs on 2024-T3. ${ }^{8}$ They, too, noted $\mathrm{Fe}, \mathrm{C}$, and $\mathrm{N}$ present in high proportions in the outer regions of the coating, but also found these elements present through the entire thickness of the coating. No conclusive evidence for the presence of ferrocyanide or preferential association of ferro- or ferricyanide with $\mathrm{Cu}$-rich IMCs was noted.

Recently, it was proposed that $\mathrm{Fe}(\mathrm{CN})_{6}^{3-}$ operates to increase the film-forming chromate-to-chromic reduction reaction, which is normally slow on aluminum. ${ }^{2}$ Raman and infrared spectroscopy of solutions and coatings showed that $(i) \mathrm{Fe}(\mathrm{CN})_{6}^{3-}$ was readily reduced during mechanical abrasion of $\mathrm{Al}$ alloys and that $\mathrm{Fe}(\mathrm{CN})_{6}^{4-}$ was rapidly oxidized back to $\mathrm{Fe}(\mathrm{CN})_{6}^{3-}$ by $\mathrm{CrO}_{3}$, and (ii) the formation of $\mathrm{Cr}^{\mathrm{III}}$ $\mathrm{Cr}^{\mathrm{VI}}$ mixed oxide was significantly accelerated in the presence of ferricyanide. Coating characterization indicated the presence of a Berlin green $\left(\mathrm{Fe}^{3+}-\mathrm{CN}-\mathrm{Fe}^{3+}\right)$ polymer and $\mathrm{Fe}(\mathrm{CN})_{6}^{3-}$ physisorbed on a $\mathrm{Cr}(\mathrm{OH})_{3}$ polymer. No other compounds derived from $\mathrm{Fe}(\mathrm{CN})_{6}^{3-}$ in solution were detected in the coating, although it was noted that the measurements were not spatially resolved and that compounds formed by interactions of $\mathrm{Fe}(\mathrm{CN})_{6}^{3-}$ with IMCs may have been present in quantities below detection limits. In this scheme, the key contribution of ferricyanide was to increase coating weight not by selfincorporation but by accelerating the film-forming $\mathrm{Cr}^{\mathrm{VI}}$ to $\mathrm{Cr}^{\mathrm{III}}$ reduction reaction.

In this study, Raman microscopy with $\sim 2 \mu$ m lateral resolution was used to map the lateral variations in the concentration of major CCC components to understand better the interaction of ferricyanide with microstructurally heterogeneous Al alloy surfaces and to understand its role in locally modifying the $\mathrm{Cr}^{\mathrm{VI}}$ to $\mathrm{Cr}^{\mathrm{III}}$ reduction reaction. A specially prepared $\mathrm{Al}-\mathrm{Cu}-\mathrm{Mg}$ ingot containing the $\mathrm{AlCuMg}$, $\mathrm{Al}_{2} \mathrm{CuMg}, \mathrm{Al}_{5} \mathrm{CuMg}_{4}$ intermetallic compounds, and $\mathrm{Al}-\mathrm{Cu}-\mathrm{Mg}$ and Al-Mg solid solution phases was treated with a commercial chromating solution (Alodine ${ }^{\mathrm{TM}} 1200$ ), then examined with spatially resolved Raman spectroscopy. Results show that the intensity of the 
$860 \mathrm{~cm}^{-1}$ band characteristic of the $\mathrm{Cr}^{\mathrm{III}}-\mathrm{Cr}^{\mathrm{VI}}$ mixed oxide decreases as the $\mathrm{Cu}$ content of the phase increases. Raman spectra also indicate the formation of a $\mathrm{Cu}-\mathrm{CN}$ surface complex on $\mathrm{Cu}$-rich IMCs, which appears to suppress $\mathrm{Cr}^{\mathrm{VI}}$ reduction and formation of the $\mathrm{Cr}^{\mathrm{III}}$ $\mathrm{Cr}^{\mathrm{VI}}$ mixed oxide. This behavior is shown to apply directly to $\mathrm{CCC}$ formation on IMCs in 2024-T3. The consequences of these results to corrosion protection of AA2024-T3 are also considered.

\section{Experimental}

Materials.-A specially cast ingot was synthesized by charging an alumina crucible with $21.25 \mathrm{~g}$ of $99.999 \% \mathrm{Al}, 20.00 \mathrm{~g}$ of $99.99 \% \mathrm{Cu}$, and $8.75 \mathrm{~g}$ of $99.9 \% \mathrm{Mg}$. The charge was heated to $990^{\circ} \mathrm{C}$ at a rate of $25^{\circ} \mathrm{min}^{-1}$ and held for 30 min to insure full melting. The melt was mechanically agitated, then cooled at $7^{\circ} \mathrm{min}^{-1}$ to $510^{\circ} \mathrm{C}$ and held for $65 \mathrm{~h}$. The melt was finally cooled to room temperature at $5^{\circ} \mathrm{min}^{-1}$. The compositions of the various phases in the ingot were determined previously by electron-probe microchemical analysis, ${ }^{9}$ and were subsequently verified by energy-dispersive spectroscopy (EDS) in this study. The presence of the $\mathrm{Al}_{2} \mathrm{CuMg}$ and $\mathrm{AlCuMg}$ intermetallic compounds was also verified by X-ray diffraction (XRD) in the earlier study. ${ }^{9}$ The $\mathrm{Al}_{x} \mathrm{Cu}_{y} \mathrm{Mg}_{z}$ ingot $(2 \times 1.6 \mathrm{~cm})$ was epoxy mounted and polished mechanically with 14, 9, and $5 \mu \mathrm{m}$ Si:C Buehler (Lake Bluff, IL) papers in water. Air-drying of the ingot followed the polishing steps.

A $99.999 \%$ Cu 5 mm diam rod (Goodfellow, Huntingdon, UK), AA 2024-T3 $(1 \times 1 \mathrm{~cm}$, Aluminum Company of America, obtained from Joseph T. Ryerson and Son, Inc.) were all epoxy mounted and metallographically polished in water with 14,9 , and $5 \mu \mathrm{m} \mathrm{Si}$ C Buehler polishing paper. $\mathrm{K}_{3} \mathrm{Fe}(\mathrm{CN})_{6}, \mathrm{NaF}, \mathrm{K}_{2} \mathrm{ZrF}_{6}, \mathrm{KBF}_{4}$, and $\mathrm{K}_{2} \mathrm{CrO}_{4}$ were used as purchased from Alfa Aesar.

Alodine $^{\mathrm{TM}}$ 1200S powder (Henkel Surface Technologies, Madison Heights, MI) and Barnstead Nanopure water (resistivity > $18 \mathrm{M} \Omega$ ) were used in recommended concentrations ( $1.9 \mathrm{~g}$ powder in $250 \mathrm{~mL}$ of water) and $\mathrm{pH}$ adjusted to 1.3 to 1.4 with concentrated $\mathrm{HNO}_{3}$. In all cases, a room-temperature Alodine immersion was used, followed by a Nanopure rinse and air-drying. *Alodine (starAlodine) denotes a dip similar to Alodine in all species concentrations and $\mathrm{pH}$, without the presence of chromium. Specifically, *Alodine is composed of $14.5 \mathrm{mM} \mathrm{NaF}, 15 \mathrm{mM} \mathrm{KBF}_{4}, 2 \mathrm{mM} \mathrm{K} \mathrm{ZrF}_{6}$, $3 \mathrm{mM} \mathrm{K}_{3} \mathrm{Fe}(\mathrm{CN})_{6}$ adjusted to $\mathrm{pH} 1.3$ to 1.4 with the addition of concentrated $\mathrm{HNO}_{3}$. When the polyphase ingot was treated with Alodine, it was not galvanically coupled to AA 2024.

Raman spectroscopy.-All spectroscopy was performed on a Dilor XY Raman microprobe (Horiba-ISA, Inc., Edison, NJ). All Raman spectra were taken using the $514.5 \mathrm{~nm}$ line of a Coherent Innova 300 argon ion laser in $180^{\circ}$ sampling geometry with a holographic notch filter. Two Pellin-Broca prisms were used to remove plasma lines. A Spectrum One (Hariba-ISA) charge coupled device (CCD) detector was cooled with liquid nitrogen to $-140^{\circ} \mathrm{C}$ and measures $2000 \times 800$ pixels. The ingot was sampled with a 50 times magnification MPlan Olympus f/0.44 objective (numerical aperture $(\mathrm{NA})=0.75$ ), while the AA2024 intermetallics were sampled using a 100 times magnification MPlan Olympus f/0.24 objective (NA = $0.9)$. The slits were set at $100 \mu \mathrm{m}$ for all experiments.

Labspec version 2.06 spectral software by Dilor S.A. (HoribaISA, Inc., Edison NJ) was used to record all spectral data from the Dilor XY before converting it to Grams/32 format (version 4.02, level 1 spectral software by Galactic Industries). Raman images and maps were manipulated using Labspec software. Spatial and spectral averaging was used where possible to give the best representation of the surface.

$A E S$ and EDS.-AES measurements were performed on a Physical Electronics 680 Spectrometer. EDS measurements were performed on a Philips XL-30 FEG SEM. All phases were analyzed by EDS for elemental composition. The polished ingot was scratched with an $\mathrm{X}$ to provide a positional fix and was placed in the vacuum chamber for $10 \mathrm{~h}$ prior to measurements to desorb water and weakly bound adsorbates. The ingot was depth profiled by AES after ini- tial polishing and then again after a $3 \mathrm{~s}$ dip in Alodine solution (because of the sensitivity of the instrument, a full $5 \mathrm{~min}$ dip would form a film too thick to sample reasonably with depth profiling). All AES was performed at $10.0 \mathrm{keV}$ and $1 \mathrm{nA}$, while EDS was run at $20.0 \mathrm{keV}$. AES argon ion sputtering was used for depth profiling the water-polished and Alodine-coated $\mathrm{Al}_{x} \mathrm{Cu}_{y} \mathrm{Mg}_{z}$ ingot phases. Iongun parameters were $1 \mathrm{keV}$ and $5 \mu \mathrm{A}$, sputtering $\mathrm{SiO}_{2}$ at a rate of $2.85 \mathrm{~nm} / \mathrm{min}$. A $2 \times 2 \mathrm{~mm}$ area was sputtered off with $\mathrm{Ar}^{+}$.

Electrochemistry.-All corrosion potentials were performed in an $\mathrm{H}$-cell, separated by a glass frit, with $0.1 \mathrm{M} \mathrm{NaCl}$ on one side and the solution of interest (Alodine or $0.1 \mathrm{M} \mathrm{NaCl}$ ) on the opposite side. A platinum auxiliary electrode was used (wire or flag) in all cases, as well as a Bioanalytical Systems (West Lafayette, IN) $\mathrm{Ag} / \mathrm{AgCl}$ reference electrode. A Gamry (Warminster, PA) CMS100 potentiostat was used to record all electrochemical data. To avoid referenceelectrode contamination through the glass frit, the longest period of time in a solution was $1 \mathrm{~h}$. Usually, 5 min runs were performed, with a Nanopure water rinse in between for the reference electrode. Open-circuit potential (OCP) measurements are taken in the abovementioned solutions with the ingot as the working electrode.

Profilometry.-14, 9, and $5 \mu \mathrm{m}$ Buehler papers were used for metallographic polishing 12 samples of AA2024 alloy which were previously epoxy mounted. These were further polished with $1,0.3$, and $0.05 \mu \mathrm{m}$ Buehler alumina powders slurried with Nanopure water on Buehler polishing cloth. A low rotational speed was used to help polishing (30 to 50 revolutions/min). All samples were immediately hot-air dried after polishing. These samples were Alodine dipped for times between 1 and 10 min of immersion (two samples each for 1 , 2, 3, 4, 5, and 10 min of immersion time). The Tencor Alpha-Step 200 (KLA-Tencor, San Jose, CA) was used for all profilometry measurements. A $0.05 \mu \mathrm{m}$ radius tip was used to scan a $1 \mathrm{~mm}$ line centered on the epoxy/2024 metal edge. Height resolution was better than $100 \AA$ A. Each treated sample had three edge profiles performed on it (all on the same edge). Samples with level epoxy baselines and reproducible coating height curves were chosen for further Raman study. Galactic software (Grams) was used to correct offset and baseline the surface profile.

The epoxy/2024 metal edge point was chosen on the profilometry scan as the beginning of the sharpest increase in film thickness. The start of the sharpest increase was also set at 0 for the height (thickness) axis, and the remaining film profile was adjusted accordingly. For correlation with Raman data later, the three height profiles were averaged after the edge point was aligned and zeroed for all three runs.

Samples 10 (1 min Alodine dip time) and 40 (4 min dip) were found to be best, based on these criteria, and were selected to be used for further Raman studies. Other samples possessed greater surface roughness, lack of thickness precision between profilometry runs, or baseline uncertainty (due to curvature or large indention). A Raman measurement was performed every $10 \mu \mathrm{m}$ from the edge for $30 \mathrm{~s}$ with two integrations at each point averaged with $3.6 \mathrm{~mW}$ power at the sample.

\section{Results}

In the first series of experiments, CCCs were formed on a cast polyphase ingot containing the intermetallic compounds $\mathrm{AlCuMg}$, $\mathrm{Al}_{2} \mathrm{CuMg}, \mathrm{Al}_{5} \mathrm{CuMg}_{4}$, and two solid-solution phases $\mathrm{Al}_{24} \mathrm{Cu}_{2} \mathrm{Mg}_{7}$ and $\mathrm{Al}_{8} \mathrm{Mg}(0.7 \% \mathrm{Cu})$. Figure 1 is an optical micrograph showing the coarse structure of the ingot and the arrangement of the various phases. The intermetallic compounds, which solidified first as dendrites or needles, exhibit globular or lenticular morphologies in this metallographic cross section. These regions are ten or more micrometers in width and can be several millimeters in length. The solid-solution phases solidified last in the interdendritic spaces. These regions are tens of micrometers in width and length except for small regions where the two phases appeared to solidify with a eutectic-like morphology. Overall, this ingot consists of discrete, coarse phases with widely varying compositions. Since the phase dimensions are on the order of $10 \mu \mathrm{m}$, this sample is well-suited for Raman imaging stud- 


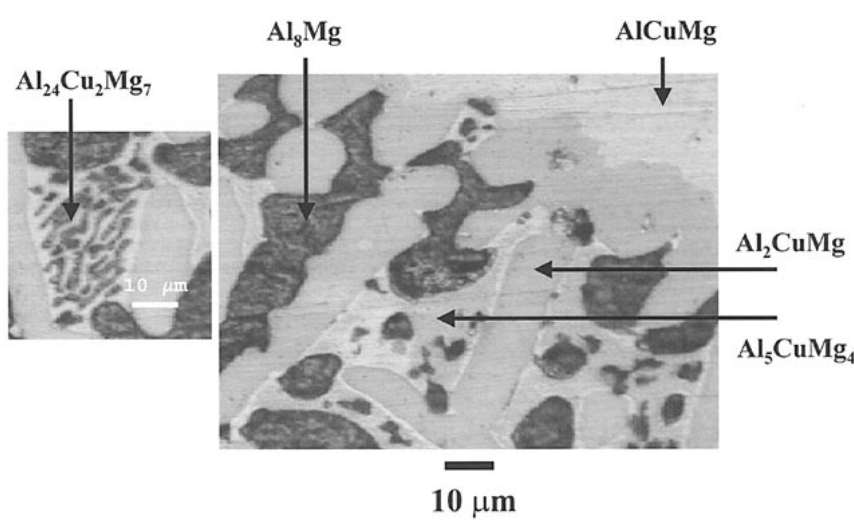

Figure 1. Optical micrograph of the polyphase $\mathrm{Al}_{x} \mathrm{Cu}_{y} \mathrm{Mg}_{z}$ ingot after polishing in water and treatment with Alodine.

ies. Upon observation with video microscopy of the CCC-treated ingot, the $\mathrm{AlCuMg}$ and $\mathrm{Al}_{2} \mathrm{CuMg}$ phases appeared to be less colored than the other phases, possibly implying a thinner CCC film.

The water-polished cross section of the ingot was Alodine treated for 5 min at room temperature, then subjected to Raman imaging. Figure 2 shows a false-color-intensity map of the Raman scattering in the $800-910 \mathrm{~cm}^{-1}$ range superimposed on the micrograph of Fig. 1. More intense red color denotes higher Raman intensity in the 800$910 \mathrm{~cm}^{-1}$ region. The Raman band centered at $860 \mathrm{~cm}^{-1}$ is characteristic of the $\mathrm{Cr}^{\mathrm{III}}-\mathrm{Cr}^{\mathrm{IV}}$ mixed oxide in Alodine CCCs. ${ }^{10}$ The $860 \mathrm{~cm}^{-1}$ band is most intense on the $\mathrm{Al}_{8} \mathrm{Mg}$ solid-solution phase and least intense on $\mathrm{AlCuMg}$. The $860 \mathrm{~cm}^{-1}$ band intensity lies between these extremes for the $\mathrm{Al}_{2} \mathrm{CuMg}, \mathrm{Al}_{5} \mathrm{Mg}_{4} \mathrm{Cu}$, and the eutectic phase, $\mathrm{Al}_{24} \mathrm{Cu}_{2} \mathrm{Mg}_{7}$. Figure 2 also shows individual Raman spectra averaged over the regions indicated by rectangles. In general, the intensity of the $860 \mathrm{~cm}^{-1}$ band varies inversely with the $\mathrm{Cu}$ content of the phase on which the measurement is made.

To determine if CCC film thickness was related to $860 \mathrm{~cm}^{-1}$ intensity, a separate profilometry experiment was carried out. In this experiment, an Alodine coating was applied to 2024-T3, and the sample was examined both by profilometry and Raman spectroscopy. The $860 \mathrm{~cm}^{-1}$ intensity was then compared to the local film thickness determined from profilometry. Figure 3 shows three superimposed profilometry traces across the interface between epoxy and AA-2024-T3, after polishing and Alodine treatment (1 min, room temperature). The CCC thickness increases with distance from the epoxy and presumably becomes constant at some point out of profilometer range. Raman spectra with $\sim 2 \mu \mathrm{m}$ lateral spatial resolution were obtained at many distances from the epoxy/alloy junction (which are indicated in Fig. 3), and the $860 \mathrm{~cm}^{-1}$ peak area was determined at each distance. A plot of Raman peak area vs. observed CCC thickness is shown in Fig. 4. Although the data are scattered, a positive linear relationship reasonably describes the relationship between $860 \mathrm{~cm}^{-1}$ peak area and film thickness. These results support the notion that the $860 \mathrm{~cm}^{-1}$ band area is proportional to film thickness, although variations in focus, power density, and collection parameters would make it difficult to determine thickness directly from a given Raman intensity unless the conditions of Fig. 4 are reproduced exactly. Provided the laser and Raman scattered light are not attenuated significantly within the thin CCC film and the film
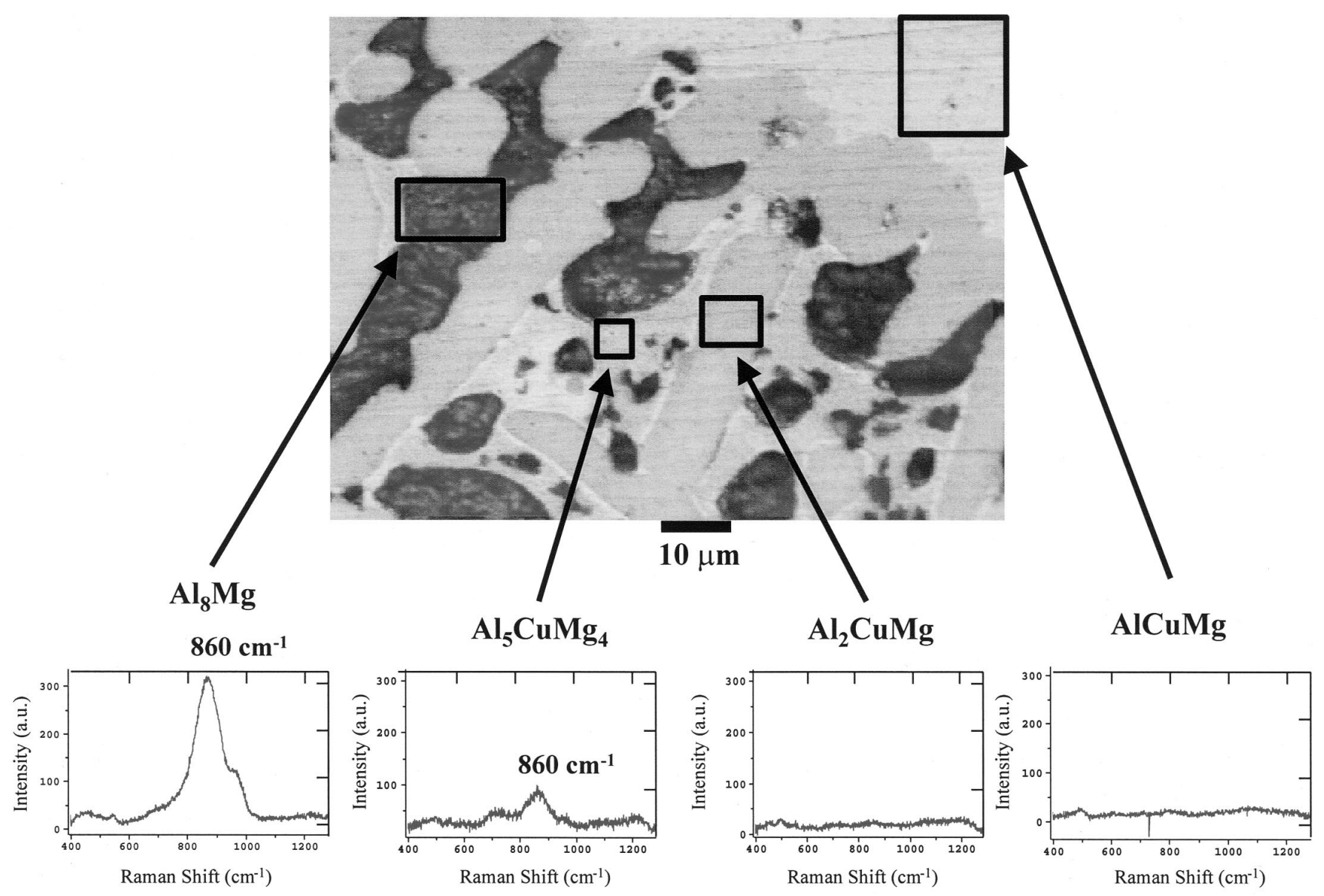

Figure 2. False color intensity map and spatially resolved Raman spectra of the polyphase ingot after CCC formation at room temperature for 5 min in Alodine solution. Intensity of red color superimposed on the optical micrograph indicates the peak area of the $800-910 \mathrm{~cm}^{-1}$ Raman shift region. Each inset is the average of spectra for at least six different spots within the indicated region. 


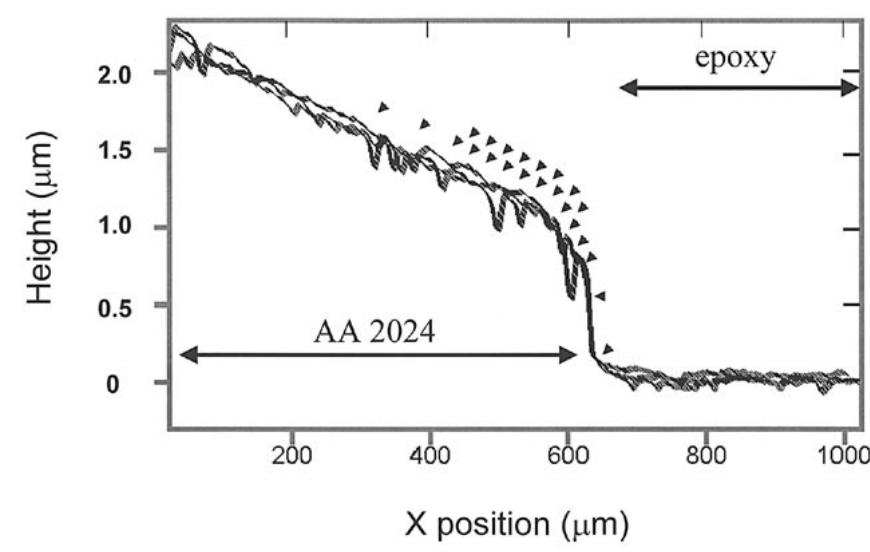

Figure 3. Solid lines are three repetitive profilometer scans of the edge of an epoxy-mounted AA 2024-T3 sample polished with $0.05 \mu \mathrm{m}$ alumina in water followed by a $1 \mathrm{~min}$ dip in room-temperature Alodine solution. Arrows indicate the positions at which the Raman spectra for Fig. 4 were obtained.

composition is homogeneous with depth, a linear relationship between intensity and thickness is expected for a given sample.

Auger depth profiles during sputtering of conversion coatings on the various phases in the ingot confirm that conversion coatings are

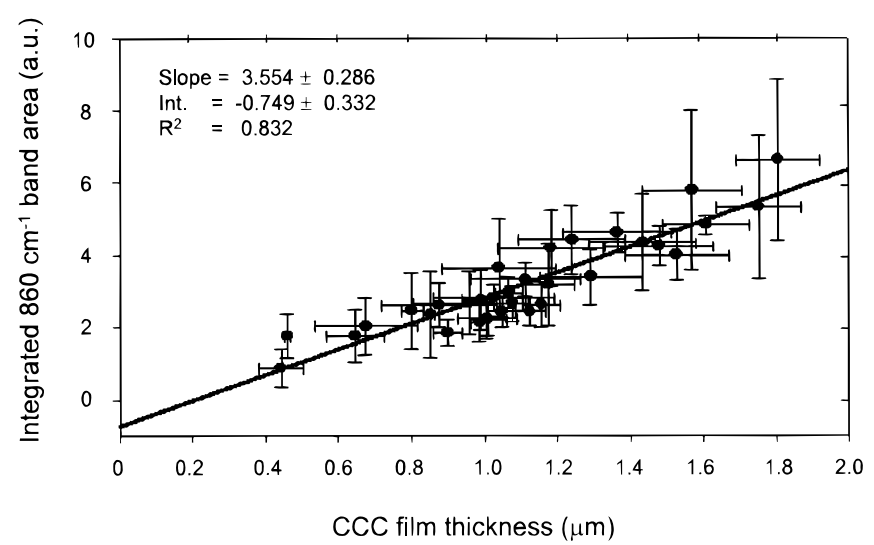

Figure 4. Relationship between Raman $860 \mathrm{~cm}^{-1}$ band area and film thickness determined from profilometry, as in Fig. 3. The Raman lateral spatial resolution was $\sim 2 \mu \mathrm{m}(50 \mathrm{X}$ objective), and two different Alodine-treated AA-2024 samples contributed to the data set. Error bars indicate the standard deviation for three independent observations of three profilometer traces and associated Raman spectra.

thinner on $\mathrm{Cu}$-rich phases. $\mathrm{CCC}$ coatings were formed on the ingot using a $3 \mathrm{~s}$ Alodine treatment at room temperature. The short Alo-

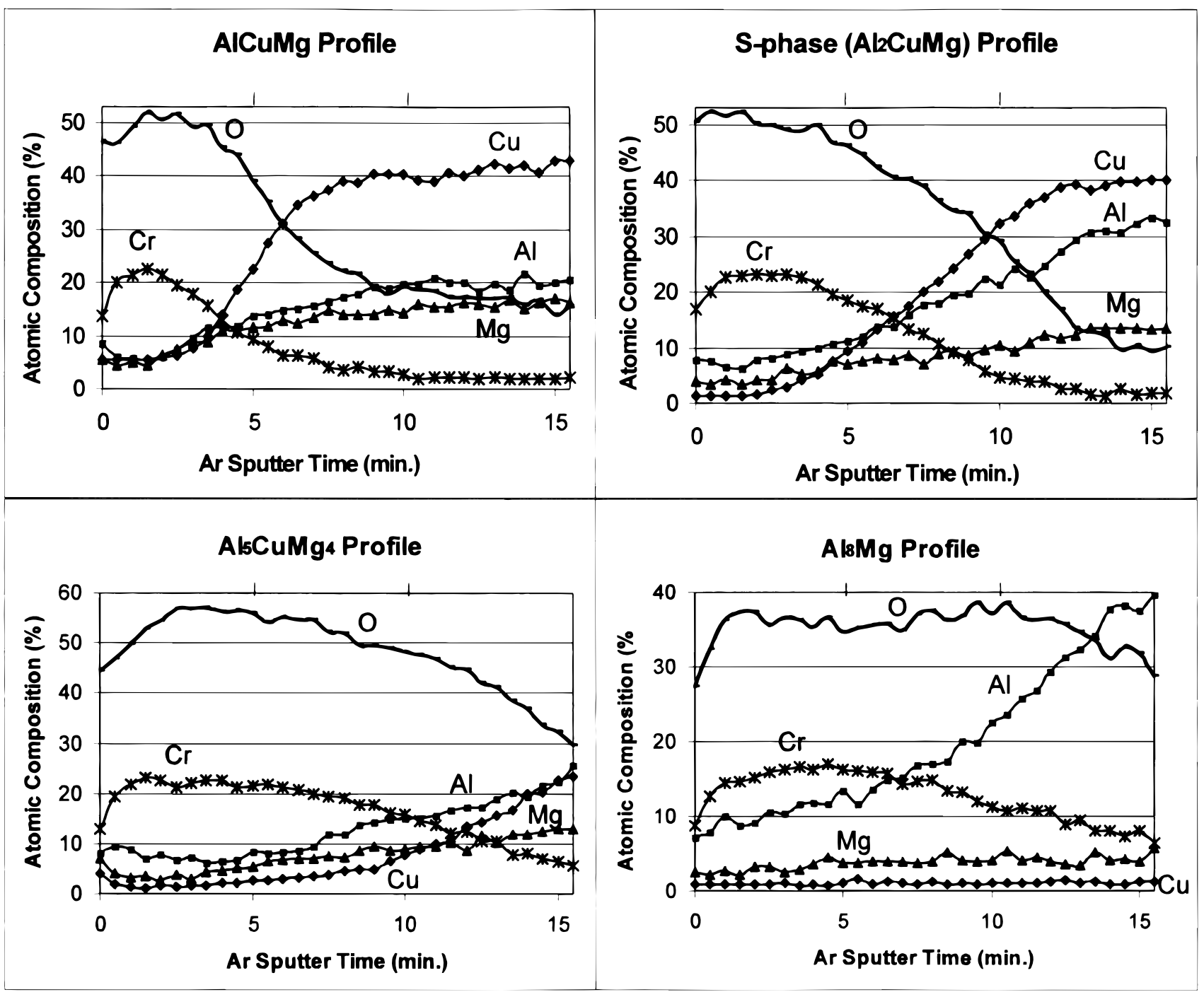

Figure 5. Auger depth profiles for ingot phases $\mathrm{AlCuMg}, \mathrm{Al}_{2} \mathrm{CuMg}, \mathrm{Al}_{5} \mathrm{CuMg}_{4}$, and $\mathrm{Al}_{8} \mathrm{Mg}$ following a $3 \mathrm{~s}$ room-temperature Alodine treatment. Sputteringbeam current was $5 \mu \mathrm{A}$ of $1 \mathrm{kV} \mathrm{Ar}^{+}$ions, yielding an approximate sputtering rate of $28.5 \mathrm{~A} / \mathrm{min}$ for $\mathrm{SiO}_{2}$. 


\begin{tabular}{|c|c|c|c|c|}
\hline \multirow{2}{*}{$\begin{array}{l}\text { Empirical } \\
\text { formula }\end{array}$} & \multicolumn{3}{|c|}{ EDS composition } & \multirow{2}{*}{$\begin{array}{c}50 \% \mathrm{Cr} \text { sputtering } \\
\text { time }^{\mathrm{a}}\end{array}$} \\
\hline & $\% \mathrm{Al}$ & $\% \mathrm{Cu}$ & $\% \mathrm{Mg}$ & \\
\hline $\mathrm{AlCuMg}$ & 36.7 & 29.9 & 33.5 & $4.5 \mathrm{~min}$ \\
\hline $\mathrm{Al}_{2} \mathrm{CuMg}$ & 48.4 & 22.3 & 23.6 & $8.0 \mathrm{~min}$ \\
\hline $\mathrm{Al}_{5} \mathrm{CuMg}_{4}$ & 52.2 & 11.3 & 36.5 & $12.5 \mathrm{~min}$ \\
\hline $\mathrm{Al}_{24} \mathrm{Cu}_{2} \mathrm{Mg}_{7}$ & 72.8 & 6.1 & 21.1 & N/A \\
\hline $\mathrm{Al}_{8} \mathrm{Mg}$ & 88.2 & 0.7 & 11.2 & $13.5 \mathrm{~min}$ \\
\hline
\end{tabular}

dine treatment was required to produce a sufficiently thin CCC for Auger depth profiling. Profiles of atomic composition as a function of sputtering time are shown in Fig. 5 for $\mathrm{AlCuMg}, \mathrm{Al}_{2} \mathrm{CuMg}$, $\mathrm{Al}_{5} \mathrm{CuMg}_{4}$, and $\mathrm{Al}_{8} \mathrm{Mg}$. $\mathrm{Al}_{24} \mathrm{Cu}_{2} \mathrm{Mg}_{7}$ was not sampled due to its heterogeneous composition. All sampled phases showed chromium and oxygen on the surface, indicating some chromium deposition over the entire surface. The chromium concentration peaks at about $20 \%$ in each case, but the oxide thickness varies from phase to phase. $\mathrm{AlCuMg}$ has a relatively thin layer of $\mathrm{Cr}$, with the chromium largely absent after 5 min of $\mathrm{Ar}^{+}$sputtering. On $\mathrm{Al}_{5} \mathrm{CuMg}_{4}$ and $\mathrm{Al}_{8} \mathrm{Mg}$, however, the $\mathrm{Cr}$ signal persists much longer, at least 10-15 min. The sputtering time at which the $\mathrm{Cr}$ atom percentage decreases to half its maximum value is approximately 4.5, 8.0, 11.5, and $12.5 \mathrm{~min}$ for

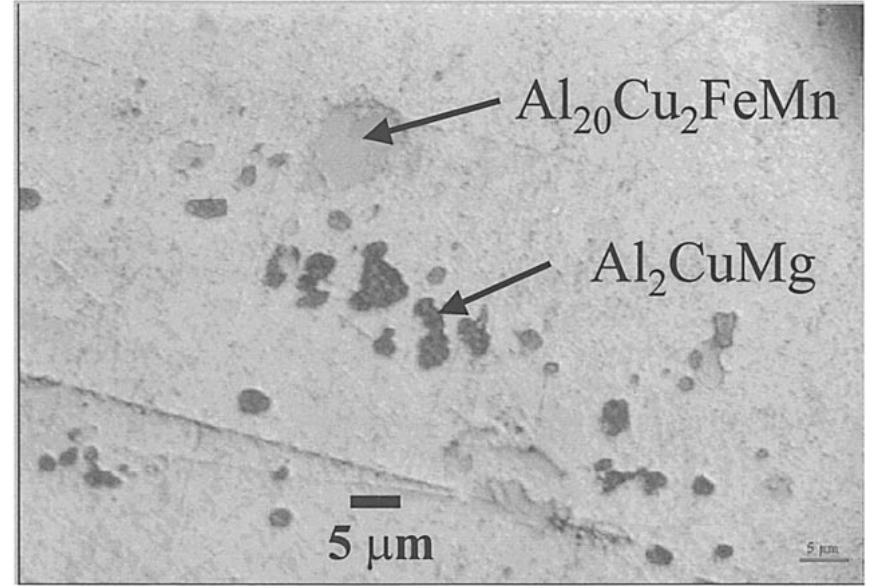

Figure 6. Optical image of AA-2024-T3 after metallographic polishing in water with $0.05 \mu \mathrm{m}$ alumina. Identifications of intermetallic particles are based on EDS.

$\mathrm{AlCuMg}, \mathrm{Al}_{2} \mathrm{CuMg}, \mathrm{Al}_{5} \mathrm{CuMg}_{4}$, and $\mathrm{Al}_{8} \mathrm{Mg}$, respectively. The phase compositions are indicated in Table I, along with the sputtering time required to reduce the $\mathrm{Cr}$ concentration by $50 \%$. These results indicate a thicker chromium-containing film over $\mathrm{Al}_{8} \mathrm{Mg}$ and $\mathrm{Al}_{5} \mathrm{CuMg}_{4}$ than over $\mathrm{AlCuMg}$ and $\mathrm{Al}_{2} \mathrm{CuMg}$. The order of the thickness of the $\mathrm{Cr}$ layer determined by Auger depth profiling matches that determined from Raman intensity. Since AES is significantly more sensi-

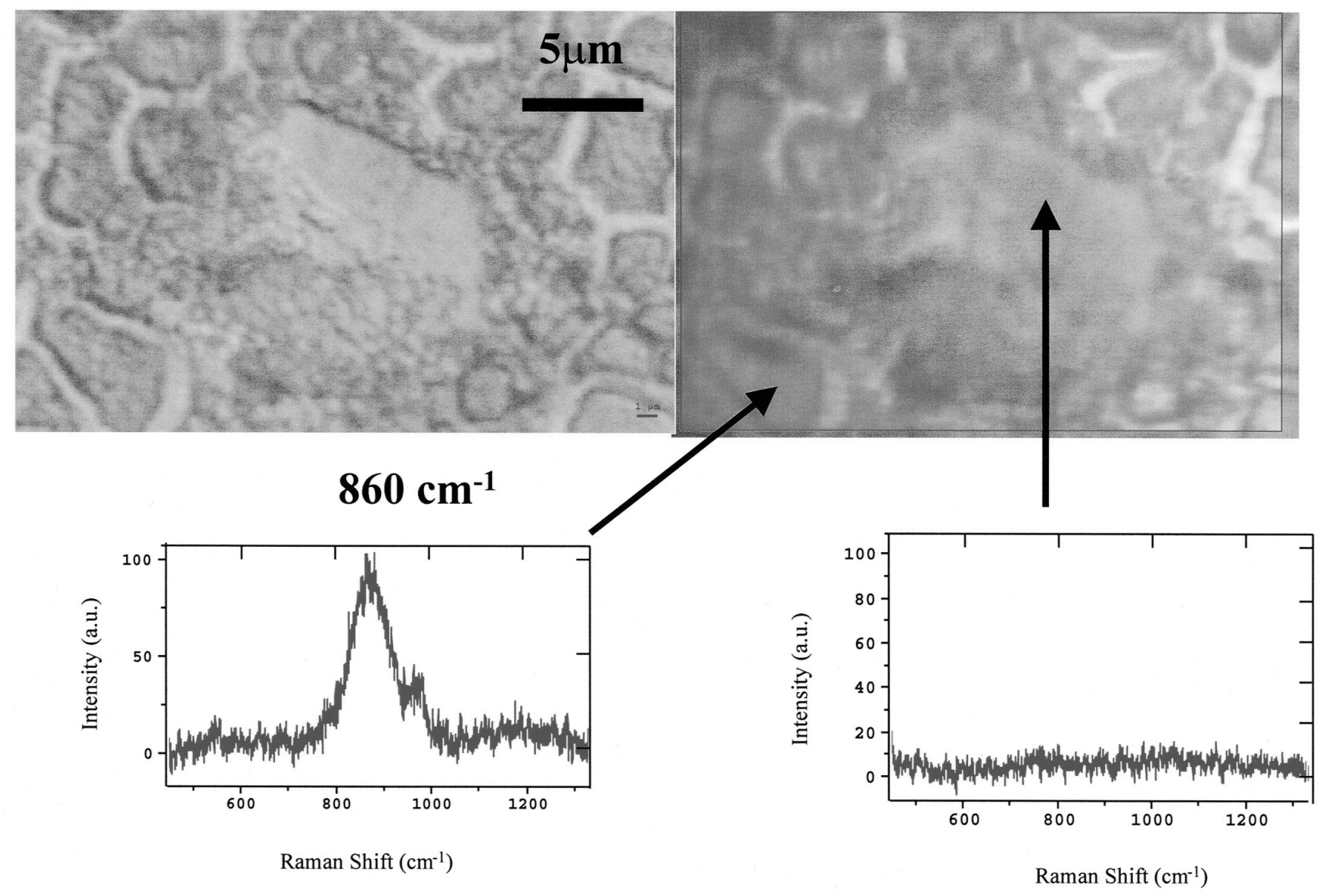

Figure 7. Optical micrograph (left) and false-color overlay of $800-910 \mathrm{~cm}^{-1}$ intensity (right) for AA-2024 following a 5 min Alodine treatment. Feature in center is an $\mathrm{Al}_{20} \mathrm{Cu}_{2} \mathrm{FeMn}$ intermetallic compound, and insets show Raman spectra obtained on and off the particle. Raman image was obtained with a $15 \times 13$ spatial grid, 100 times objective, $5-10 \mathrm{~mW}$ at sample, $50 \mathrm{~min}$ total acquisition time. 


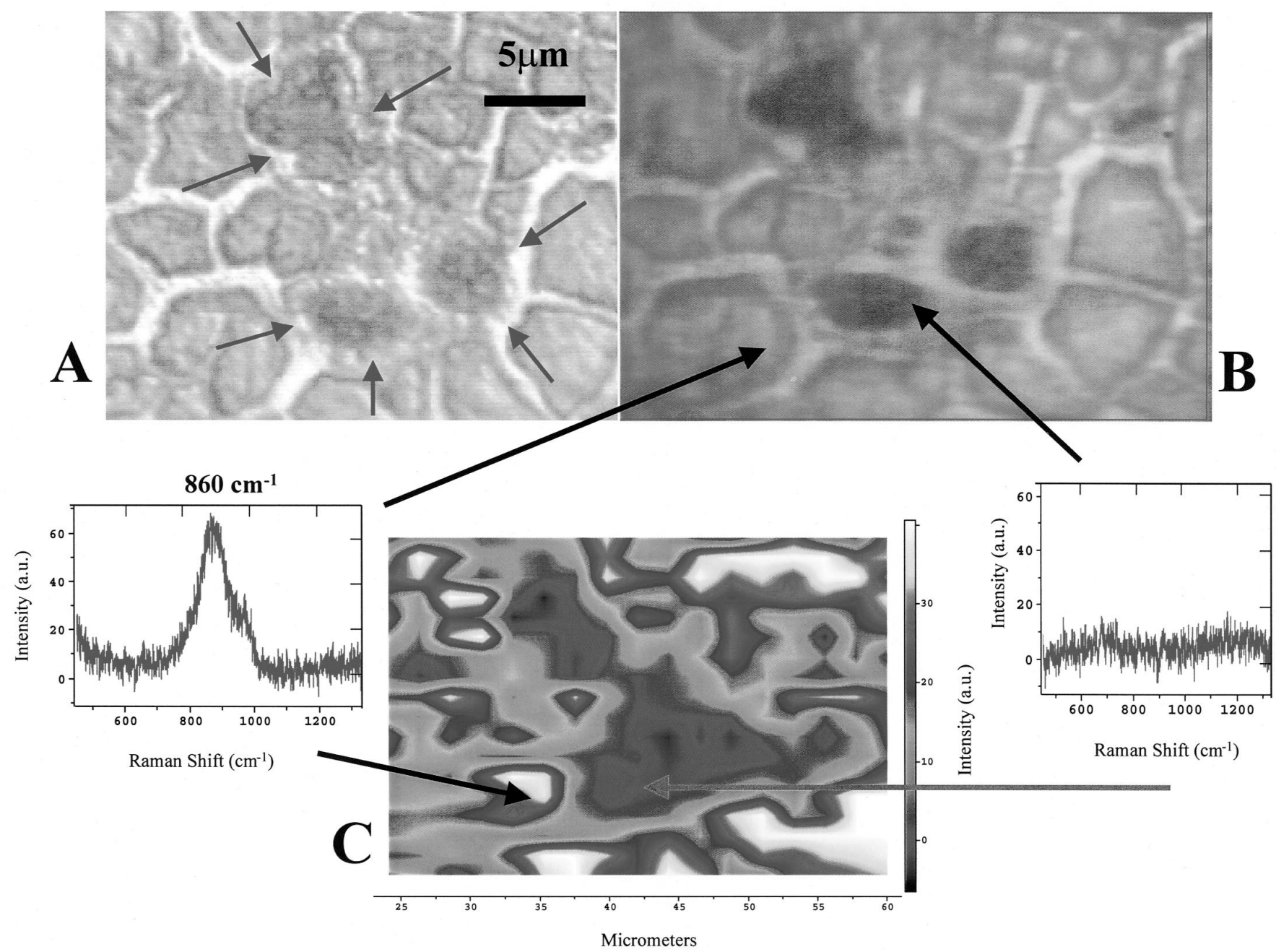

Figure 8. Micrograph (A) and Raman overlay (B) of an S-phase particle $\left(\mathrm{Al}_{2} \mathrm{CuMg}\right)$ in AA-2024 following CCC formation. Conditions same as Fig. 7, except a $17 \times 18$ spatial grid was used. Red arrows on A indicate location of S-phase particles, and red color on B indicates intensity of the $860 \mathrm{~cm}^{-1}$ Raman band. False-color map (C) indicates 800-910 $\mathrm{cm}^{-1}$ Raman intensity of region in Fig. 8A. Color scale on right indicates magnitude of $800-910 \mathrm{~cm}^{-1}$ peak area. Insets show Raman spectra obtained at the indicated regions.

tive than Raman spectroscopy, the $\mathrm{Cr}$ detected on the $\mathrm{Cu}$-rich phases by AES is below the Raman detection limit. The Auger depth profiles did not reveal an excess concentration of $\mathrm{Cu}$ on the surface, indicating that sample polishing and preparation did not appear to cause dealloying or copper redistribution.

Raman imaging also shows that CCC formation is inhibited over IMCs present in AA2024-T3. Figure 6 shows a typical distribution of constituent IMCs in 2024-T3. Large $\mathrm{Al}_{20} \mathrm{Cu}_{2} \mathrm{FeMn}$ particles and smaller S-phase particles $\left(\mathrm{Al}_{2} \mathrm{CuMg}\right)$ were readily detected. Figures 7 and 8 show companion optical micrographs and superimposed Raman $860 \mathrm{~cm}^{-1}$ maps collected in the vicinity of $\mathrm{Al}_{20} \mathrm{Cu}_{2} \mathrm{FeMn}$ and $\mathrm{Al}_{2} \mathrm{CuMg}$ particles, respectively. The false-color image of Fig. $8 \mathrm{C}$ provides a semiquantitative indication of $\mathrm{CCC}$ film thickness for the same region. The $860 \mathrm{~cm}^{-1}$ intensity is much weaker over the $\mathrm{Al}_{2} \mathrm{CuMg}$ particle, as expected based on the preceding results. The $\mathrm{Al}_{20} \mathrm{Cu}_{2} \mathrm{FeMn}$ phase was not present in the ingot discussed, but the decrease in $860 \mathrm{~cm}^{-1}$ intensity over the particle indicates CCC formation is inhibited over this IMC also.

Raman spectra of CCC films show features in the CN stretching region $\left(2000-2200 \mathrm{~cm}^{-1}\right)$, which are associated with the presence of $\mathrm{Fe}(\mathrm{CN}) 6^{3-14-}$ on coated surfaces (Fig. 9). There are significant differences in the $\mathrm{CN}$ stretch region of spectra collected from each of the phases. The eutectic phase, $\mathrm{Al}_{24} \mathrm{Cu}_{2} \mathrm{Mg}_{7}$, and the $\mathrm{Al}_{8} \mathrm{Mg}$ solid-solution phase exhibit the 2095 and $2145 \mathrm{~cm}^{-1}$ bands which are observed for a CCC on AA-2024 and correspond to physisorbed $\mathrm{Fe}(\mathrm{CN}) 6_{6}^{3-} .^{2}$
In contrast, $\mathrm{AlCuMg}$ and $\mathrm{Al}_{5} \mathrm{Mg}_{4} \mathrm{Cu}$ exhibit a distinct $2175 \mathrm{~cm}^{-1}$ band similar to that observed when pure copper is exposed to $\mathrm{Fe}(\mathrm{CN})_{6}^{3-} \cdot{ }^{11}$ The intensities of the $\mathrm{CN}$ band vary with surface preparation and oxide coverage, but the band frequencies are important indicators of the nature of the $\mathrm{CN}^{-}$substrate interaction. In this respect, the presence of the $2171-2175 \mathrm{~cm}^{-1}$ band distinguishes the film formed on $\mathrm{AlCuMg}, \mathrm{Al}_{2} \mathrm{CuMg}$, and $\mathrm{Al}_{5} \mathrm{Mg}_{4} \mathrm{Cu}$ after exposure to $\mathrm{Fe}(\mathrm{CN})_{6}^{3-}$. Similarly, the presence of the 2095 and $2145 \mathrm{~cm}^{-1}$ bands on the Al-rich phases characterizes the surface films on those phases. The Raman spectra of Fig. 9 indicate that a distinct cyano surface species forms when the $\mathrm{Cu}$-rich phases and pure $\mathrm{Cu}$ are exposed to the Alodine solution. A possible assignment of the $2175 \mathrm{~cm}^{-1}$ band observed on $\mathrm{Cu}$ and $\mathrm{Cu}$ phases is $\mathrm{Cu}-\mathrm{CN}$ or $\mathrm{Cu}-\mathrm{NC}-\mathrm{Fe}(\mathrm{CN})_{5}$ resulting from chemisorption of $\mathrm{Fe}(\mathrm{CN})_{6}^{3-}$ on copper. It is possible that this chemisorbed layer interferes with $\mathrm{CCC}$ formation, leading to a thinner $\mathrm{CCC}$ over $\mathrm{Cu}$-rich phases. To explore the possibility that chemisorbed $\mathrm{Fe}(\mathrm{CN})_{6}^{3-14}-$ forms a passivating layer that inhibits $\mathrm{CCC}$ formation on $\mathrm{Cu}$-rich phases, a mixed-phase ingot was treated with a synthetic Alodine solution containing all components except $\mathrm{Cr}^{\mathrm{VI}}$ (denoted as *Alodine). After a 1 min treatment of $*$ Alodine, the ingot was rinsed and thoroughly dried for 2 days, then exposed to conventional Alodine solution for $5 \mathrm{~min}$. After this treatment, a CCC was not visibly formed, and Raman spectroscopy revealed that the $860 \mathrm{~cm}^{-1}$ signal was absent from all phases except $\mathrm{Al}_{24} \mathrm{Cu}_{2} \mathrm{Mg}_{7}$. The Raman signal on $\mathrm{Al}_{24} \mathrm{Cu}_{2} \mathrm{Mg}_{7}$ was shifted to $850 \mathrm{~cm}^{-1}$ and was much 


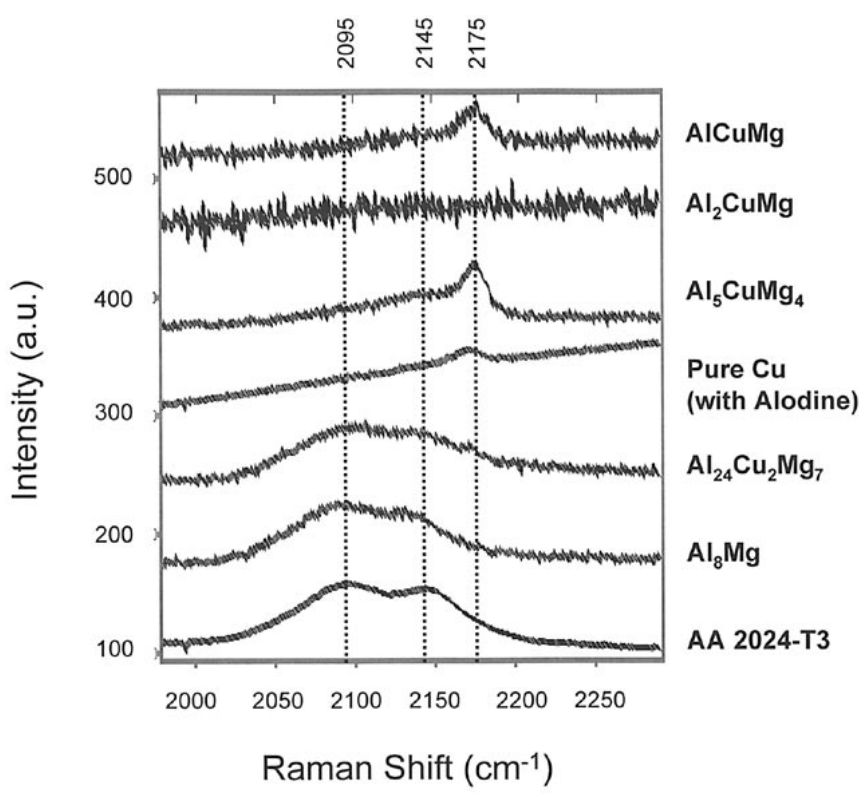

Figure 9. Raman spectra of $1980-2280 \mathrm{~cm}^{-1}$ region of each phase of the ingot, AA-2024, and pure copper. Each spectrum is the average of at least six spatial locations on each phase. Ingot was treated in room-temperature Alodine for $3 \mathrm{~min}$, AA 2024 for $5 \mathrm{~min}$, and $\mathrm{Cu}$ for $10 \mathrm{~min}$.

weaker than that observed with conventional Alodine treatment. OCP measurements also suggested that the *Alodine pretreatment resulted in sample passivation. Figure 10 compares the OCP for the ingot and AA-2024 during Alodine treatment with and without the *Alodine pretreatment. The OCP is much more positive if the ingot was exposed to *Alodine before Alodine treatment. A sample of AA-2024 treated similarly showed the same effect with the potential remaining near $-240 \mathrm{mV}$ for $125 \mathrm{~s}$ before decreasing to lower potentials. The Raman $860 \mathrm{~cm}^{-1}$ intensity of AA-2024 matrix phase appeared unaffected by $\mathrm{Fe}(\mathrm{CN})_{6}^{3-/ 4-}$ pretreatment.

\section{Discussion}

Ferricyanide additions constitute no more than $15 \%$ by weight of the solid ingredients used to make-up Alodine $1200 \mathrm{~S} .{ }^{19}$ As such, ferricyanide is fairly categorized as a minor chemical addition. However, in the presence of $\mathrm{Fe}(\mathrm{CN})_{6}^{3-}$, the coating formation rate is greatly increased with a concomitant decrease in processing time. ${ }^{13}$ Therefore its use in $\mathrm{CCC}$ formulations designed for $\mathrm{Al}$ alloys carries great practical advantage.

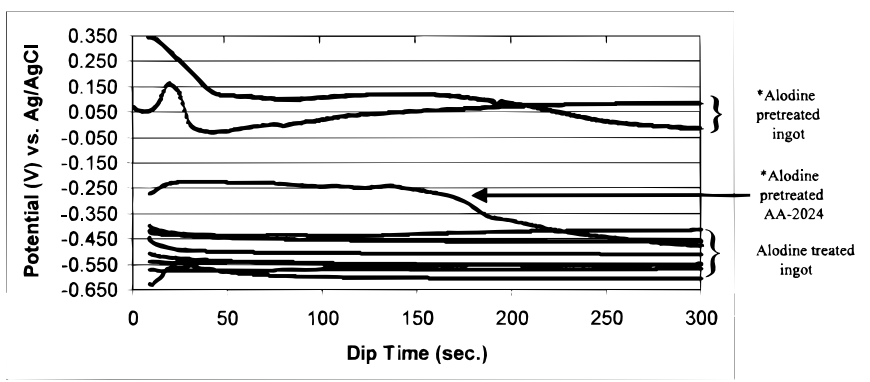

Figure 10. OCP of polyphase ingot during treatment in room-temperature Alodine solution. Top two samples were pretreated with *Alodine, which contains all Alodine components except $\mathrm{Cr}^{\mathrm{VI}}$, then dried in air for 2 days before exposure to conventional Alodine. The average OCP for conventional treatment was $-515 \mathrm{mV} v s . \mathrm{Ag} / \mathrm{AgCl}$, while the *Alodine-pretreated samples exhibited an average OCP of $-26 \mathrm{mV} v s$. $\mathrm{Ag} / \mathrm{AgCl}$. Traces are shown for seven conventional (treated with Alodine), two *Alodine-pretreated ingots, and one AA-2024-T3 sample pretreated with Alodine.
It has been known for many years that $\mathrm{Cu}$-bearing $\mathrm{Al}$ alloys are highly susceptible to corrosion. Even the best chromate corrosion protection systems do not always provide acceptable levels of corrosion protection on alloys that contain $4-6 \% \mathrm{Cu}$ or more. The results of this study suggest that part of the reason may lie in the fact that there is a negative interaction between a minority ingredient in CCC formulations, ferricyanide, and minority phases in $\mathrm{Al}-\mathrm{Cu}-\mathrm{X}$ alloys, $\mathrm{Cu}$-rich IMCs, that significantly undermines the effectiveness of this corrosion-protection strategy.

Before proposing a mechanism to explain the effects of IMCs on CCC formation, several observations deserve special note. First, the weak $860 \mathrm{~cm}^{-1}$ band intensity over $\mathrm{AlCuMg}, \mathrm{Al}_{2} \mathrm{CuMg}$, and $\mathrm{Al}_{5} \mathrm{CuMg}_{4}$ in the ingot and over the IMC inclusions in 2024-T3 indicate either that a CCC film is not forming on these phases or a film is forming which does not contain levels of $\mathrm{Cr}^{\mathrm{III}}-\mathrm{Cr}^{\mathrm{VI}}$ mixed oxide observable by Raman. While it has been shown that coating nucleation does occur rapidly on IMCs in 2024-T3 during exposure to Alodine $1200 \mathrm{~S}$ solution, ${ }^{14}$ determination of the local coating chemistry has not been made until now. Furthermore, the atomic force microscopy (AFM) methods employed sample the very early generation of a thin CCC film, while Raman spectroscopy samples thicker, multilayer films. Second, AES depth profiling indicates a Cr-containing film over all phases of the ingot, but the film is significantly thinner over copper-rich phases ( $\mathrm{AlCuMg}, \mathrm{Al}_{2} \mathrm{CuMg}$, and $\mathrm{Al}_{5} \mathrm{CuMg}_{4}$ ) compared to copper-poor phases $\left(\mathrm{Al}_{8} \mathrm{Mg}\right)$. Third, cyano species are observed on $\mathrm{Cu}$-rich IMC phases in the absence or presence of chromate. The cyanide stretch was observed on pure copper treated with *Alodine, and its frequency corresponds to a $\mathrm{Cu}-\mathrm{CN}$ vibration at $2170 \mathrm{~cm}^{-1}$. ${ }^{11}$ This band is completely distinguishable from the $\mathrm{CN}$ stretches observed in a CCC. Fourth, pretreatment of the ingot with a solution containing $\mathrm{Fe}(\mathrm{CN})_{6}^{3-}$ has a dramatic effect on subsequent Alodine treatment, preventing $\mathrm{CCC}$ formation and causing a $\sim 500 \mathrm{mV}$ positive shift in the OCP during Alodine treatment.

Previous investigations concluded that $\mathrm{CCC}$ formation requires at least two steps, reduction of $\mathrm{Cr}^{\mathrm{VI}}$ to insoluble $\mathrm{Cr}^{\mathrm{III}}$ oxy/hydroxide, mediated by $\mathrm{Fe}(\mathrm{CN})_{6}^{3-14-}$, and adsorption of $\mathrm{Cr}^{\mathrm{VI}}$ to the $\mathrm{Cr}^{\mathrm{III}}$ oxy/ hydroxide. ${ }^{2}$ We have also reported that $\mathrm{Cr}^{\mathrm{VI}}$ adsorbs spontaneously to hydrated $\mathrm{Cr}(\mathrm{OH})_{3}$, and the product is the yellow $\mathrm{Cr}^{\mathrm{III}}-\mathrm{Cr}^{\mathrm{IV}}$ mixed oxide with its characteristic $860 \mathrm{~cm}^{-1}$ Raman band. The weakness of this band over $\mathrm{AlCuMg}$ and $\mathrm{Al}_{2} \mathrm{CuMg}$ implies that $\mathrm{Cr}^{\mathrm{III}}-\mathrm{Cr}^{\mathrm{IV}}$ mixed oxide is prevented from forming either because $\mathrm{Cr}^{\mathrm{VI}}$ is not reduced to $\mathrm{Cr}^{\mathrm{III}}$, or because $\mathrm{Cr}^{\mathrm{VI}}$ is not adsorbing to $\mathrm{Cr}^{\mathrm{III}}$. The latter case is unlikely, since $\mathrm{Cr}^{\mathrm{VI}}$ spontaneously adsorbs to $\mathrm{Cr}^{\mathrm{III}}$ oxy/hydroxide. The most likely cause of the absence of $\mathrm{Cr}^{\mathrm{III}}-\mathrm{Cr}^{\mathrm{IV}}$ mixed oxide over $\mathrm{AlCuMg}$ and $\mathrm{Al}_{2} \mathrm{CuMg}$ is inhibition of the reduction of $\mathrm{Cr}^{\mathrm{VI}}$ to $\mathrm{Cr}^{\mathrm{III}}$.

The reduction of $\mathrm{Cr}^{\mathrm{VI}}$ to $\mathrm{Cr}^{\mathrm{III}}$ during CCC formation is strongly dependent upon redox mediation by ferricyanide, in which $\mathrm{Fe}(\mathrm{CN})_{6}^{3-}$ is reduced by $\mathrm{Al}$ to $\mathrm{Fe}(\mathrm{CN})_{6}^{4-}$, then $\mathrm{Cr}^{\mathrm{VI}}$ is reduced to $\mathrm{Cr}^{\mathrm{III}}$ by $\mathrm{Fe}(\mathrm{CN})_{6}^{4-}$. If $\mathrm{Fe}(\mathrm{CN})_{6}^{3-}$ reduction were somehow inhibited on IMCs compared to the $\mathrm{Al}$ matrix, $\mathrm{Cr}{ }^{\mathrm{III}}$ and $\mathrm{CCC}$ formation would be slower on IMCs. There is substantial evidence from the literature and the current results that such inhibition can occur. ${ }^{3,15-17}$ $\mathrm{Fe}(\mathrm{CN})_{6}^{3-}$ is known to adsorb on $\mathrm{Cu}, \mathrm{Ni}, \mathrm{Pt}$, etc., with partial decomposition, to form chemisorbed cyano species, and possibly Prussian blue, an Fe-CN-Fe polymer. ${ }^{15-18}$ The $2170 \mathrm{~cm}^{-1}$ band observed after exposure of pure copper to *Alodine indicates deposition of a cyano species on copper, even without aluminum or chromium present. Adsorbed $\mathrm{Fe}(\mathrm{CN})_{6}^{3-}$ species decrease the electron-transfer rate for $\mathrm{Fe}(\mathrm{CN})_{6}^{3-14-}$ on platinum electrodes to the point of complete deactivation in severe cases. ${ }^{12}$ Taken together, these observations lead to the hypothesis that $\mathrm{Fe}(\mathrm{CN})_{6}^{3-}$ adsorbs on copper-rich regions on the ingot surface, possibly with some decomposition to form a $\mathrm{Cu}-\mathrm{CN}$ linkage or an $\mathrm{Fe}-\mathrm{CN}-\mathrm{Cu}$ bridging group. The resulting deposit inhibits electron transfer between the surface and solutionphase $\mathrm{Fe}(\mathrm{CN})_{6}^{3-/ 4-}$, thus decreasing $\mathrm{Cr}^{\mathrm{III}}$ generation and $\mathrm{CCC}$ formation. A schematic of this mechanism is shown in Fig. 11.

If this model is correct, then pretreatment of the alloy surface with *Alodine might affect CCC growth, since redox kinetics with 


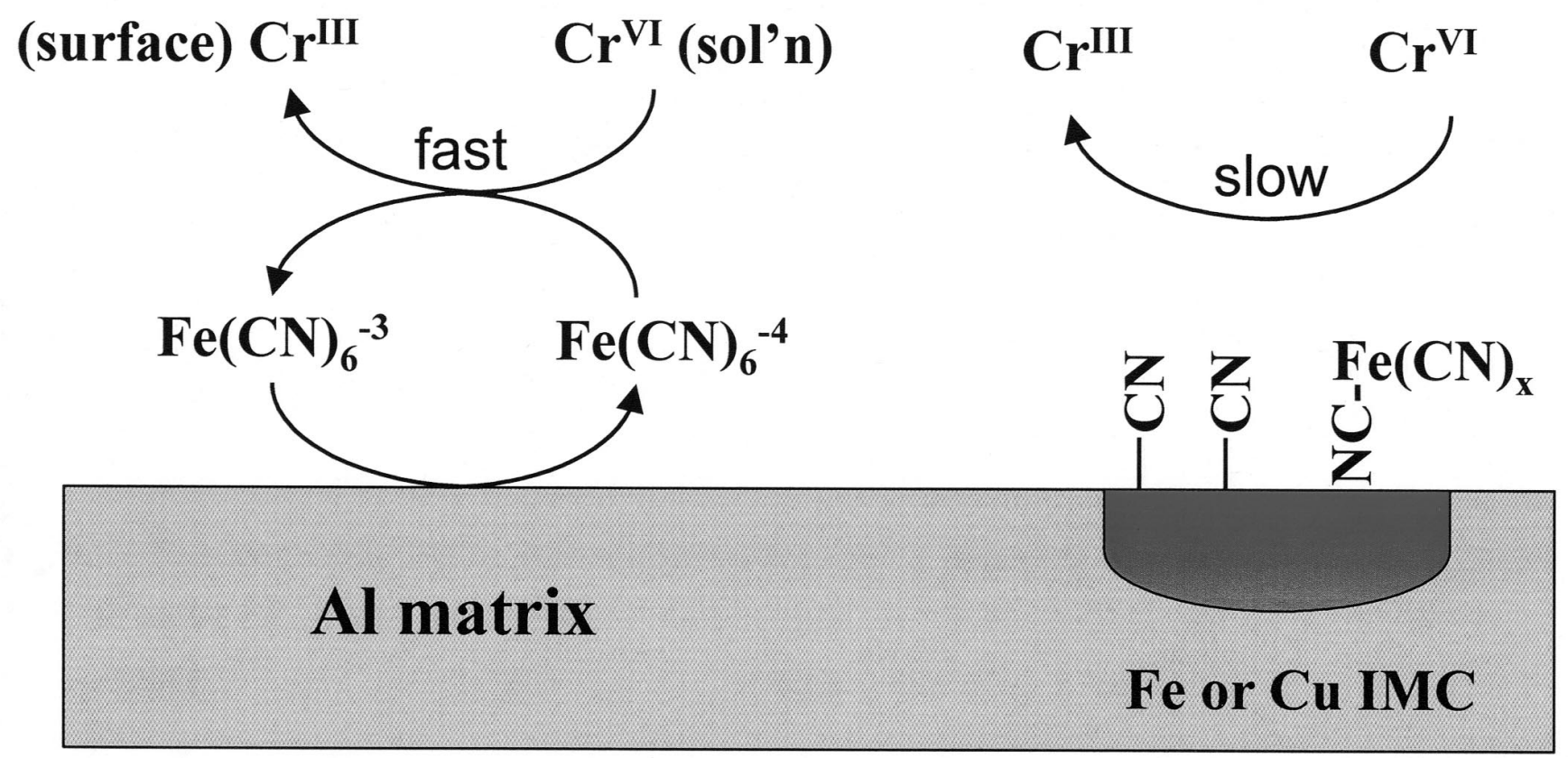

Figure 11. Schematic of possible inhibition of CCC formation over intermetallic regions on an aluminum alloy. Chemisorption of cyanide or ferricyanide may inhibit redox mediation by $\mathrm{Fe}(\mathrm{CN})_{6}^{3-/ 4-}$, thus reducing the rate of $\mathrm{Cr}^{\text {III }}$ formation. $\mathrm{Fe}(\mathrm{CN})_{x}$ denotes adsorbed and possibly degraded ferricyanide.

the $\mathrm{Fe}(\mathrm{CN}){ }_{6}^{3-}$ in the Alodine bath might be inhibited. The results of Fig. 10 indicate the profound effect of *Alodine on CCC formation, even when the pretreatment occurred several days before Alodine exposure. A CCC detectable by Raman spectroscopy was not formed on any phase (although $\mathrm{Al}_{24} \mathrm{Cu}_{2} \mathrm{Mg}_{7}$ showed a small peak shifted to $850 \mathrm{~cm}^{-1}$ ), and the positive potential shift during Alodine treatment implies inhibition of reduction by the surface. Observations of the ingot pretreated with *Alodine are completely consistent with a mechanism based on inhibition of CCC formation by a CN-containing film which forms more rapidly on copper-rich IMCs.

The behavior of IMCs in AA-2024 is similar to that on the multiphase ingot. The $860 \mathrm{~cm}^{-1}$ Raman intensity on the $\mathrm{Al}_{20} \mathrm{Cu}_{2} \mathrm{FeMn}$ and S-phase inclusions is lower than on the aluminum matrix. Pretreatment with *Alodine did not appear to have an observable effect on CCC formation on AA-2024. It is possible that the copper content of the ingot phases differed from the IMCs in AA-2024, causing a stronger interaction with $\mathrm{Fe}(\mathrm{CN}){ }_{6}^{3-}$. Alternatively, the fractional area of aluminum is much higher in AA-2024 than in the multiphase ingot, thus changing conditions enough to reduce $\mathrm{Fe}(\mathrm{CN}) 6_{6}^{3-}$ adsorption from *Alodine.

Preliminary attempts were made to replace the $\mathrm{Fe}(\mathrm{CN})_{6}^{3-/ 4-}$ in Alodine with a mediator which did not contain cyanide. $\mathrm{IrCl}_{6}^{2-13-}$ also accelerates CCC film growth but had a reduced effectiveness compared to $\mathrm{Fe}(\mathrm{CN})_{6}^{3-14-}$ when the ingot was treated with an Alodine solution containing $\mathrm{IrCl}_{6}^{2-13-}$ instead of $\mathrm{Fe}(\mathrm{CN})_{6}^{3-/ 4-}$. The coverage of $\mathrm{CCC}$ on $\mathrm{Al}_{2} \mathrm{CuMg}$ increased significantly, and an $\mathrm{AlCuMg}$ it increased slightly. For example, the $860 \mathrm{~cm}^{-1}$ intensity on $\mathrm{Al}_{2} \mathrm{CuMg}$ after the Alodine//rCl 6 - $/ 3-$ treatment was $\sim 19 \%$ as large as that on $\mathrm{Al}_{8} \mathrm{Mg}$, while standard Alodine yielded a negligible $860 \mathrm{~cm}^{-1}$ intensity on $\mathrm{Al}_{2} \mathrm{CuMg}\left(<2 \%\right.$ as large as on $\left.\mathrm{Al}_{8} \mathrm{Mg}\right)$. This observation supports the proposal that $\mathrm{Fe}(\mathrm{CN})_{6}^{3-}$ or $\mathrm{CN}^{-}$adsorption on $\mathrm{Al}_{2} \mathrm{CuMg}$ inhibits $\mathrm{CCC}$ formation. However, the fact that the $860 \mathrm{~cm}^{-1}$ intensity is still small over AlCuMg with $\mathrm{IrCl}_{6}^{3-12-}$ mediation indicates that other factors may be involved in the inhibition of CCC formation.

When considering the implications of the current results for corrosion protection of AA-2024 by chromate, several possibilities arise. First, the low concentration of $\mathrm{Cr}^{\mathrm{VI}}$ in the film over the IMCs may comprise a defect in the anticorrosion film. If $\mathrm{Cr}^{\mathrm{VI}}$ is the active protective agent, the unprotected IMC may act as a site for pit initiation or filiform corrosion. Second, the absence of chromate over IMCs may significantly affect the local charge density, changing it from a neutral or anionic region expected for adsorbed chromate or $\mathrm{Cr}^{\mathrm{III}}-\mathrm{Cr}^{\mathrm{VI}}$ mixed oxide to a cationic site expected for hydrated $\mathrm{Cr}^{\mathrm{III}}$ or $\mathrm{Al}^{\mathrm{III}}$ oxides. A cationic site may attract chloride and stimulate corrosion. Third, the adsorbed cyanide and/or ferricyanide may significantly affect electron-transfer kinetics at IMCs. We have already hypothesized that adsorbed cyanide inhibits $\mathrm{Fe}(\mathrm{CN})_{6}^{3-14-}$ kinetics during CCC formation, but it may also affect "field" reactions such as oxygen reduction or $\mathrm{Al}$ oxidation. The effects of cyanide modification of IMCs on electron-transfer kinetics are currently unknown but are likely to be substantial. The heterogeneous distribution of CCC observed in the Raman images indicates clearly that IMC phases in the ingot or in AA 2024 result in an imperfect CCC film. By one or more of the mechanisms noted above, this imperfect film may result in reduced corrosion protection.

The Ohio State University assisted in meeting the publication costs of this article.

\section{References}

1. N. J. Newhard, Jr., Met. Finish., 69 (July 1972).

2. L. Xia and R. L. McCreery, J. Electrochem. Soc., 146, 3696 (1999).

3. P. L. Hagans and C. M. Haas, in Metals Handbook, Vol. 5, Surface Engineering, p. 405, ASM International, Metals Park, OH (1994).

4. J. A. Treverton and N. C. Davies, Metals Technology, 4, 480 (Oct 1977).

5. J. A. Treverton and N. C. Davies, Surf. Interface Anal., 3, 194 (1981).

6. P. L. Hagans and C. M. Haas, Surf. Interface Anal., 21, 65 (1994).

7. F. W. Lytle, R. B. Greegor, G. L. Bibbins, K. Y. Blohowiak, R. E. Smith, and G. D. Tuss, Corros. Sci., 37, 349 (1995).

8. A. E. Hughes, R. J. Taylor, and B. W. R. Hinton, Surf. Interface Anal., 25, 223 (1997).

9. R. G. Buchheit, L. P. Montes, M. A. Martinez, J. Micheal, and P. F. Hlava, J. Electrochem. Soc., 146, 4424 (1999).

10. L. Xia and R. L. McCreery, J. Electrochem. Soc., 145. 3083 (1998)

11. G. Laufer, T. F. Scaaf, and J. T. Huneke, J. Chem. Phys., 73, 2973 (1980).

12. W. Huang and R. L. McCreery, J. Electroanal. Chem., 326, 1 (1992).

13. N. J. Newhard, Met. Finish, 49 (July 1972).

14. J. R. Waldrop and M. W. Kendig, J. Electrochem. Soc., 145, 1, L11 (1998).

15. Henkel und Cie. G.m.b.H., Fr. Pat. 1,598,686 (1970); Chem. Abstr. 74:56730.

16. D. Y. Dollman, Br. Pat. 1,139,390 (1969); Chem. Abstr. 70:60330.

17. K. Katsuma, DE. Pat. 4,407,315 (1994); Chem. Abstr. 121:240655.

18. S. Sinha, B. D. Humphrey, and A. B. Bocarsly, Inorg. Chem., 23, 203 (1984).

19. Material Data Safety Sheet for Alodine 12005. 